\title{
Divergência genética entre cinco genótipos de melão rendilhado
}

\author{
Adriana Antonieta do Nascimento Rizzo ${ }^{1}$, Leila Trevizan Braz ${ }^{1}$
}

UNESP, Depto. de Produção Vegetal, Via de Acesso Prof. Paulo Donato Castellane s/n, 14.870-000, Jaboticabal-SP, E-mail: drarizzo@fcav.unesp.br

\section{RESUMO}

Estimou-se a divergência genética entre cinco genótipos de melão rendilhado (Cucumis melo var. reticulatus Naud.) (JAB-20, JAB21, JAB-22, JAB-23 e 'Bônus $\mathrm{n}^{\circ}$ 2') e determinou-se qual a contribuição relativa das 16 características avaliadas [ $\mathrm{n}^{\circ}$ médio de flores masculinas, hermafroditas/planta; produção total de frutos $/ \mathrm{m}^{2}$, peso médio dos frutos comerciáveis; diâmetro médio transversal e longitudinal do fruto (DMTF e DMLF); diâmetro médio transversal da inserção do pedúculo (DMTP); espessura média do mesocarpo e epicarpo (EMM e EME); diâmetro médio longitudinal e transversal do lóculo (DMTL e DMLL); proporção da cavidade (PC); desprendimento de sementes (DS); teor de sólidos solúveis totais (SST), pH e acidez titulável (AT)] na divergência genética. Obtiveram-se dois grupos de similaridade: I- JAB-20, JAB-21 e 'Bônus n'2' e II- JAB22 e JAB-23. As características DMLF, DMTP, DMLL, DS e SST foram as que mais contribuíram para a divergência genética entre os genótipos.

Palavras-chave: Cucumis melo var. reticulatus Naud., divergência genética.

\begin{abstract}
Genetic divergence among five muskmelon cultivars

The genetic divergence of five cultivars of muskmelon was estimated (Cucumis melo var. reticulatus Naud) (JAB-20, JAB-21, JAB-22, JAB-23 and 'Bônus $n^{\circ} 2$ ') and the relative contribution of each 16 characteristics were determined (number of male flowers per plant; total production of fruit, weight of fruits; longitudinal and transversal diameters of fruits; thickness and color of flesh and skin; longitudinal and transversal loculos diameter of fruits; seed loosing; netting thickness; and \% total solvers solids, $\mathrm{pH}$ and total acidity) in genetic divergence. Two groups of similarity were formed between the genitors by the values of $\mathrm{D}^{2}$, one of then was constituted of the JAB-20 and JAB-21 and 'Bônus $\mathrm{n}^{\circ} 2$ ' genotypes, and another of the JAB-22 and JAB-23. The characteristics of longitudinal loculos diameters, longitudinal diameter of fruits, transversal diameter of peduncle insertion, $\%$ total solvers solids and seed loosing contributed to for genetic divergence between the progenitors.
\end{abstract}

Keywords: Cucumis melo var. reticulatus Naud., genetic divergence.

(Aceito para publicação em 03 de dezembro de 2.001)

$\mathrm{O}$ melão rendilhado (Cucumis melo var. reticulatus Naud.) apresenta vantagens comerciais em relação aos outros melões, tais como preferência de mercado, boa cotação comercial e cultivo em pequenas áreas com boa lucratividade.

Até o momento não se dispõe de cultivares adaptadas às condições brasileiras que atendam às necessidades para plantios comerciais, havendo o predomínio de utilização de sementes híbridas de origem americana ou japonesa. Para o desenvolvimento de híbridos nacionais, estudos sobre a divergência genética entre genitores tornam-se de grande interesse, pois fornecem parâmetros para a identificação de genitores que possibilitem maior efeito heterótico na progênie e maior probabilidade de recuperar genótipos superiores nas gerações seguintes (Cruz, 1990).

A análise de agrupamento tem por finalidade reunir, por algum critério de classificação, as unidades amostrais (indivíduos, objetos, locais, etc.) em vários grupos, de tal forma que exista homogeneidade dentro e heterogeneidade entre grupos (Sneath \& Sokal, 1973). Alternativamente, as técnicas de análise de agrupamento tem por objetivo dividir um grupo original de observações em vários grupos homogêneos, segundo algum critério de similaridade ou dissimilaridade (Cruz, 1990). Entre os métodos de agrupamento mais utilizados no melhoramento de plantas, citam-se os hierárquicos e os de otimização. Como exemplo de métodos de otimização, tem-se o apresentado por Tocher, que vem sendo extensivamente utilizado em análises de divergência genética de várias espécies de plantas (Rao, 1952).

Nos métodos de otimização, os grupos são formados pela adequação de algum critério de agrupamento. No método proposto por Rao (1952), citado por Cruz (1990) é estabelecido o critério de manter a distância média intragrupo sempre inferior a qualquer distância intergrupo. Esses métodos diferenciam- se dos hierárquicos por serem os grupos formados mutuamente exclusivos ou sob o contexto de teoria de conjuntos, em razão de caracterizarem por subdividir o grupo original em subgrupos não vazios, cuja interseção é nula e a união reconstitui o conjunto total (Cruz, 1990).

São poucos os trabalhos encontrados na literatura que citam o estudo da divergência genética na cultura do meloeiro. Dentre estes está o realizado por Mathew et al. (1986) que estudaram a divergência genética entre quatro variedades botânicas de meloeiro (inodorus, flexuosos, utilissimus e momordica) com relação a quatro características, sendo que dentre elas, o número de frutos por planta contribuiu com $80 \%$ da divergência total entre as variedades estudadas.

Visando dar suporte a programas de melhoramento genético dessa espécie, este trabalho teve como objetivo estimar a divergência genética entre cinco genótipos de melão rendilhado e determinar a contribuição relativa das 16 características avaliadas na divergência genética. 
Tabela 1. Medidas de dissimilaridade entre os genitores de melão rendilhado obtidas pela Distância Generalizada de Mahalanobis $\left(\mathrm{D}^{2}\right)$. Jaboticabal, UNBESP, 1998.

\begin{tabular}{lccccc}
\hline Genitores & JAB-20 & JAB-21 & JAB-22 & JAB-23 & 'Bônus n' 2' \\
\hline JAB-20 & --- & 992930,87 & 7292281,50 & 1147942,00 & 3380219,00 \\
JAB-21 & --- & --- & 3975587,75 & 44022,80 & 746884,80 \\
JAB-22 & --- & -- & --- & 3378111,00 & 2864544,00 \\
JAB-23 & --- & --- & --- & --- & 643493,50 \\
'Bônus n' 2' & --- & --- & --- & --- & --- \\
\hline
\end{tabular}

\section{MATERIAL E MÉTODOS}

O experimento foi instalado em casa de vegetação da UNESP, Campus de Jaboticabal. Foram utilizados cinco genótipos de melão rendilhado, fenotipicamente diferentes: JAB-20; JAB-21; JAB-22; JAB-23 e 'Bônus n' $2^{4}$ (que possui ciclo médio, fruto arredondado, bastante rendilhado, com casca e polpa verde quando maduro, com pequena cavidade interna, fácil desprendimento das sementes da placenta e tolerância a nematóides).

Adotou-se o delineamento em blocos ao acaso com 4 repetições e o espaçamento de $0,8 \mathrm{~m}$ entre linhas e 0,5 $\mathrm{m}$ entre plantas. A semeadura ocorreu em fevereiro/98, utilizando-se bandejas de poliestireno expandido com 128 células, preenchidas com substrato para hortaliças. As adubações de plantio e cobertura foram realizadas com base na análise do solo, seguindo recomendações para a cultura. $O$ transplantio para a casa de vegetação ocorreu quando as mudas apresentavam a primeira folha definitiva. As plantas foram tutoradas utilizando o sistema de cercas com quatro fios de arame, espaçados entre eles em 0,50 m, alcançando a altura de 2,0 $\mathrm{m}$ a partir do solo, e conduzidas verticalmente enrolando-se o ramo principal destas em fitilho fixado nos arames a medida em que a planta se desenvolvia. O solo foi desinfetado com brometo de metila, previamente ao transplantio.

Foram coletados dados referentes a: número médio de flores masculinas e hermafroditas/planta; produção total de frutos $/ \mathrm{m}^{2}$; peso médio dos frutos comerciáveis $(\mathrm{kg})$; diâmetro médio transversal e longitudinal do fruto $(\mathrm{cm})$; diâmetro médio longitudinal e transversal do lóculo $(\mathrm{cm})$, proporção da cavi- dade, diâmetro médio transversal da inserção do pedúnculo $(\mathrm{cm})$; espessura média do mesocarpo e epicarpo $(\mathrm{cm})$; coloração do mesocarpo, determinada de acordo com escala de notas (1- verde, 2- amarelo e 3- laranja); rendilhamento da casca (caracterizado por avaliação visual), desprendimento de sementes (notas: 1-difícil, 2- intermediário, 3- fácil); teor de sólidos solúveis ( ${ }^{\circ}$ Brix), obtido pela utilização de refratômetro manual; $\mathrm{pH}$, através de peagâmetro manual, e acidez titulável, obtida pela titulação com $\mathrm{NaOH}$ sobre a diluição de $20 \mathrm{~mL}$ de suco do fruto em $20 \mathrm{~mL}$ de água destilada, usando como indicador fenolftaleína. Foi realizada transformação da acidez titulável segundo Tressler \& Joslyn (1961), utilizando-se o fator de correção (volume de $\mathrm{NaOH}$ titulado x 0,32 ), que proporciona valores em gramas de ácido cítrico/100mL de solução.

A divergência genética entre os genótipos foi determinada pela distância generalizada de Mahalanobis (Mahalanobis, 1936), definida pela equação $D^{2}{ }_{i j}=\left(X_{i}-X_{j}\right)^{\prime} E^{-1}\left(X_{i}-X_{j}\right)$, onde $\mathrm{X}_{\mathrm{i}}$ e $\mathrm{X}_{\mathrm{j}}$ são os vetores médios associados aos genótipos $\mathrm{i}$ e $\mathrm{j}$ respectivamente e $E^{-1}$ é a inversa da matriz de covariância residual obtida na análise de variância multivariada. Para o cálculo da distância generalizada de Mahalanobis, as variáveis foram transformadas por condensação pivotal, em que $\mathrm{D}_{\mathrm{ii}}^{2}=\mathrm{S}\left(\mathrm{z}_{\mathrm{ij}}-\mathrm{z}_{\mathrm{i} \cdot \mathrm{j}}\right)^{2}$, onde $\mathrm{z}_{\mathrm{ij}}$ é a média do i-ésimo genótipo em relação à $\mathrm{j}$ ésima variável com variância residual igual a 1. Para a otimização dos grupos, utilizou-se a técnica de Tocher que estabelece que a média das distâncias intragrupos devem ser menores que as distâncias intergrupos (Cruz, 1990). O método requer a obtenção de matriz de dissimilaridade, sobre a qual é identifi- cado o par de indivíduos mais similar. Esses indivíduos formarão o grupo inicial. A partir daí é avaliada a possibilidade de inclusão de novos indivíduos, adotando-se o critério anteriormente citado (Cruz, 1990).

Para o cálculo da contribuição relativa dos caracteres para divergência genética foi utilizado o critério proposto por Singh (1981), baseado na estatística S.j. Considerou-se que $\mathrm{D}_{\mathrm{ii}}^{2}=\delta^{\prime} \psi^{-1} \delta$ $=\sum_{\mathrm{j}=1} \sum_{\mathrm{j}^{\prime}=1} \omega_{\mathrm{jj}} \mathrm{d}_{\mathrm{j}} \mathrm{d}_{\mathrm{j}}$, em que $\mathrm{w}_{\mathrm{jj}}$ é o elemento da $\mathrm{j}$-esima coluna da inversa da matriz de variância e covariância residuais. $\mathrm{O}$ total das distâncias envolvendo todos os pares de genótipos é dado por: $\mathrm{SSD}_{\mathrm{ii}}{ }^{2}$ $=\mathrm{S} \mathrm{D}_{\mathrm{m}}{ }^{2}=\mathrm{SS}_{\mathrm{ij}}$. Os valores percentuais de $S$.j constituíram a medida da importância relativa da variável $\mathrm{j}$ para o estudo da diversidade genética.

Os cálculos foram realizados utilizando-se o programa GENES, desenvolvido por Cruz (1997).

\section{RESULTADOS E DISCUSSÃO}

As médias de dissimilaridade entre cada par de genótipos obtidas pela Distância Generalizada de Mahalanobis $\left(D^{2}\right)$ podem ser observadas na Tabela 1 . Observa-se, pelos valores obtidos, que a cultivar JAB-21 foi a que apresentou a menor distância em relação a outro genitor, ou seja, ao JAB-23 (44022,80), enquanto o maior valor $\mathrm{D}^{2}$ ocorreu entre os genitores JAB-20 e JAB-22.

Pelos valores de $\mathrm{D}^{2}$, foi possível obter os grupos de similaridade, onde pode ser observado que três genótipos foram dispostos em um mesmo grupo de similaridade (Grupo I) JAB-20, JAB-21 e 'Bônus $n^{\circ} 2$ ' e os genótipos JAB-22 e JAB-23 num outro grupo (Grupo II). Espera-se que genótipos constantes em um mesmo grupo de similaridade, quan- 
Divergência genética entre cinco genótipos de melão rendilhado.

Tabela 2. Contribuição relativa de 16 características de melão rendilhado, na divergência genética. Jaboticabal, UNESP, 1998.

\begin{tabular}{lc}
\hline \multicolumn{1}{c}{ Características } & Contribuição relativa(\%) \\
\hline$N^{\circ}$ médio de flores masculinas/planta & 2,93 \\
$N^{\circ}$ médio de flores hermafroditas/planta & 6,49 \\
Produção total de frutos/m2 & 0,80 \\
Peso médio dos frutos & 0,06 \\
Diâmetro médio longitudinal do fruto & 26,97 \\
Diâmetro médio transversal do fruto & 3,33 \\
Diâmetro médio transversal da inserção do pedúnculo ao fruto & 10,02 \\
Espessura média do mesocarpo & 1,43 \\
Espessura média do epicarpo & 0,37 \\
Diâmetro médio transversal do lóculo & 6,79 \\
Diâmetro médio longitudinal do lóculo & 13,63 \\
Proporção da cavidade do fruto & 1,14 \\
Desprendimento de sementes & 9,81 \\
Teor de sólidos solúveis totais & 11,60 \\
Concentração hidrogeniônica média & 3,31 \\
Acidez titulável & 1,33
\end{tabular}

do cruzados entre si, exibam pouca heterose. Recomenda-se, então, a realização de cruzamentos entre genótipos de grupos distintos, ou seja, JAB-22 $\mathrm{x}$ JAB-20, JAB-22 x JAB-21, JAB-22 x 'Bônus $n^{\circ} 2$ ' ou ainda JAB-23 x JAB20, JAB-23 x JAB-21 e JAB-23 x 'Bônus $n^{\circ} 2$ '.

A distribuição dos genótipos nos grupos confirmam as maiores distâncias ocorridas entre os genótipos JAB-20 e JAB-23, que pertencem a grupos diferentes.

Na Tabela 2, observa-se a contribuição relativa de cada característica para a divergência genética. Todas as características avaliadas contribuíram para a determinação da divergência genética entre os genótipos, em maior ou menor proporção. Verifica-se entretanto, que juntas as características: diâmetro médio longitudinal do fruto e do lóculo, diâmetro médio transversal da inserção do pedúnculo ao fruto e desprendimento de sementes, contribuíram com 72,03 \% na avaliação da divergência genética entre os genótipos.

\section{AGRADECIMENTOS}

À Fundação de Amparo à Pesquisa (FAPESP) pela concessão da bolsa de mestrado.

\section{LITERATURA CITADA}

BRAZ, L.T. Estudos da heterose da capacidade combinatória visando produção de frutos e sementes de tomate (Lycopersicon esculentum Mill.) Jaboticabal, 1992. 123 p. (Tese doutorado), UNESP.
CRUZ, C.D. Aplicação de algumas técnicas multivariadas no melhoramento de plantas. Piracicaba, 1990. 188 p. (Tese doutorado).

CRUZ, C.D. Programa GENES: aplicativo computacional em genética e estatística. Viçosa: UFV, 1997. 442 p.

MAHALANOBIS, P.C. On the generalized distance in statistic. Proceedings of the National Institute of Science, Delhi, v. 2, p. 49-55, 1936.

MATHEW, S.M., GOPALAKRISHNAN, P.K., PETER, K.V. Genetic distance among five botanical varieteies of Cucumis melo. Agricultural Research Journal of Kerala, v. 24, n. 2, p. 195-6, 1986. In: Plant Breeding and Genetics (CAB: CDROOM).

RAO, R.C. Advanced statistical methods in biometric research. New York: John Wiley and Sons, 1952. $390 \mathrm{p}$.

SENEATH, P.H., SOKAL, R.R. Numerical Taxonomy; the principles and practice of numerical classification. W.H. Freeman, 1973. $573 \mathrm{p}$.

TRESSLER, D.K.; JOSLYN, M.A. Fruit and vegetable juice: processing technology. Westport, 1961.p. 1028. 